Virginia Commonwealth University VCU Scholars Compass

2005

\title{
Too quick? Log analysis of Quick Links from an academic library website
}

Jimmy Ghaphery

Virginia Commonwealth University, jghapher@vcu.edu

Follow this and additional works at: http://scholarscompass.vcu.edu/libraries_pubs

Part of the Graphics and Human Computer Interfaces Commons, and the Library and Information Science Commons

copyright Emerald Group Publishing Limited

\section{Downloaded from}

http://scholarscompass.vcu.edu/libraries_pubs/6

This Article is brought to you for free and open access by the VCU Libraries at VCU Scholars Compass. It has been accepted for inclusion in VCU Libraries Faculty and Staff Publications by an authorized administrator of VCU Scholars Compass. For more information, please contact libcompass@vcu.edu. 


\section{Too Quick?: Log Analysis of Quick Links from an Academic Library Website}

Jimmy Ghaphery

Virginia Commonwealth University Libraries

jsghaphe@,vcu.edu

Since the summer of 2001, Virginia Commonwealth University Libraries has offered a "Quick Links" menu in the top right hand side of many of its pages [Figure 1]. Transaction log files have been run in order to analyze the use of the Quick Links, and several changes have been made based on those logs. This article will discuss those findings and offer contextual ideas for the use of Quick Links in comparison to the rest of the library website.

\section{History}

In May of 2001, the Quick Links menu first appeared on the VCU Libraries website as part of a site redesign. Quick Links were viewed by the Libraries Web Redesign Task Force as a space effective method to present frequently sought after information in a consistent place throughout the site. Further, the Web Redesign Task Force felt that these Quick Links should be incorporated into the standard library headers across the majority of the site. The content of the Quick Links menu was derived from identifying popular pages and resources that were not represented on either the homepage or the standard header. This identification was done through a combination of internal discussions and analysis of web server logs. ${ }^{1}$ The resulting list of 13 items included subscription databases, library services, and university services. The Quick Links were "chunked" into sections to make it easier to scan for either databases or services [see Table 1 for a look at the evolution of Quick Links over time].

Things went swimmingly along until the following summer when a request came to the Libraries Information Technology Work Group to add an item to Quick Links. Rather than decide this out of context, the group decided to review the web server logs before determining if anything should be changed. In doing so several challenges were readily apparent as there was not a single set of statistics from which to draw conclusions. Obviously, the web server logs only included statistics for the pages that resided on the web server! Many of the Quick Links however were directed to external databases. Further, for popular pages that were on the Quick Links menu it was not possible to determine if the use of these pages was from Quick Links or some other source. Despite

\footnotetext{
${ }^{1}$ VCU Libraries uses the Wusage analytic software to measure web server logs. All references in this article to web server log data are drawn from the Wusage compilations of accesses. Accesses are recorded each time a document on the Web server is requested. More on Wusage is available at $\mathrm{http} / /$ www.boutell.com/wusage/. The transaction log data on the other hand was compiled separately from Wusage.
} 
these obstacles the group wrestled with the available data to define a revision to Quick Links that was put into production by the start of the Fall 2002 semester. This revision increased the number of Quick Links to fifteen.

Upon implementing the revised Quick Links, the group also decided to undertake a transaction log analysis in order to gain a better understanding of how this resource was being used. The Quick Links use a drop down select menu that is powered by a serverside script. As such it was a minor task to adjust that script to log each time a Quick Link was used and which specific Quick Link was chosen. The use of transaction log analysis is well established in the literature, and a recent article by Phillip M. Davis gives a succinct history of the use of such analysis (2004).

\section{2-2003 Log Analysis}

Two separate transaction logs were run during the 2002-2003 school year. The first log ran from September 2002 through November 2002 and recorded 72,446 transactions indicating which Quick Link had been selected. The Information Technology Group decided that a second log should be initiated to gather more data so that decisions would not be based solely on one part of the academic year. The second $\log (97,332$ transactions) ran from December 2002 through April 2003. Interestingly there was little difference between the two logs.

Both logs revealed that many of the fifteen total Quick Links were infrequently used, especially in comparison to the most heavily used selections. In both logs the top two items were external databases (InfoTrac OneFile and MEDLINE), and accounted for roughly $40 \%$ of the total use. InfoTrac alone drove more than one-quarter of all Quick Links usage. Likewise, the top five items (InfoTrac, MEDLINE, E-mail, Lexis, Ejournals) accounted for approximately $77 \%$ of the total use. In contrast, the bottom five items accounted for a total of just $4 \%$ of all Quick Link activity.

Upon digesting these results, several revisions were implemented. The bottom two performers (Illiad and Electronic Reference Shelf) were eliminated from Quick Links. "Search our Website" (0.8\%) was relocated from the bottom toward the top of the Quick Link list and renamed to "Sitemap" in the hopes of greater visibility. Web server logs were again consulted for any obvious additions, and a web page listing various librarian created subject guides "Research and Topic Guides" was added. Also considering the strong use of the "Check your E-mail" choice, "Blackboard", the University course management system, also debuted on the VCU Libraries Quick Links menu. To further highlight each grouping of selections, lines were added in place of the blank space between each group.

\section{Fall 2004 Transaction Log}

The issue of Quick Links had not been revisited for analysis by the Library Information Technology Group since 2003. Since that time, several minor edits as well as contextual changes had occurred. Throughout the site (including Quick Links) "Online Journals" and 
"Online Books" was changed to "Ejournals" and "Ebooks", "MEDLINE" was renamed to "MEDLINE/Pubmed", and "Dow Jones" had changed its name to "Factiva". Links to Ejournals and Ebooks were also included directly on the homepage in a new "Online Resources" section. Finally, a standard set of personal toolbar bookmarks was added to the public library computers. These bookmarks included links to E-mail access and Blackboard. Given these changes and the length of time since the last analysis, it was decided that another transaction log should run during the Fall 2004 semester.

The new log showed a similar distribution of access where the majority of use was driven by a few of the choices [Table 2]. The top two choices (InfoTrac and Pubmed) were used even more heavily at $44 \%$ compared to $40 \%$ of all use from the combined logs of 20022003. The top five choices (InfoTrac, PubMed, E-mail, Lexis, Ejournals) also remained the same accounting for $74 \%$ compared to $77 \%$ in the previous log. At the bottom end, the least used 5 items clocked in at the same $4 \%$.

There were however some significant differences between the Fall 2004 log and the combined Fall 2002/Spring 2003 log that also deserve discussion. While InfoTrac stayed atop the list with $27 \%$, the $4 \%$ growth in use of the top two items was attributable solely to an increase in MEDLINE/Pubmed requests, up from $12.7 \%$ to $16.8 \%$. Another item that had a strong showing at $6 \%$ was the newly added link to Blackboard. Among other items in the top tier of requests, Ejournals showed a marked decrease from $15.4 \%$ to $9.5 \%$. At the same time from analysis of web server logs, overall accesses to the Libraries Ejournal page increased. It is most likely that the decrease in Quick Links usage for Ejournals is attributable to the addition of the Ejournal link on the homepage itself.

The E-mail choice only declined slightly from $11.9 \%$ to $10.5 \%$, even though new personal bookmarks on public library computers also offered this choice. The need to access E-mail from the library web page would seem most likely to arise for users inside the library. From casual observation at the Reference desk, many students do use the public library computers to check E-mail. It is tempting to speculate on the overall visibility of browser customizations such as personal bookmarks on public library computers versus the addition of items to the webpage itself. In the case of adding a link for "E-journals" directly to the homepage, Quick Link usage decreased much more than for "E-mail" where a direct link was present onsite in the browser toolbar. This could be a fruitful area for further study. In addition to transaction data, the referring IP address would also be needed to in order to make strong inferences on the use of Quick Links by those inside the library versus those outside the library.

Other additions and modifications to Quick Links did not gain measurable attention in the $2004 \log$. The newly added "Research and Topic Guides" was not a frequent choice at less than $1 \%$ of all Quick Link activity. The total number of accesses through web server logs to the Research and Topic Guides page remained strong, suggesting that alternate navigation was sufficient and perhaps already established. Despite elevating "Search our Website" to the top of the Quick Links list and changing its name to "Sitemap", this selection still remained at less than $1 \%$ in relation to the other Quick Links. 


\section{Failure Points}

The logs also pointed toward difficulties with the basic interface. From 1.5 to $1.6 \%$ of Quick Link activity resulted in the end user clicking the Go Button without making a selection from the drop down menu. In the same vein, but not as significant (less than $0.1 \%$ ) there were also entries in the log where the user selected the spacer between each group of choices. Another consistent problem was that the server-side script was not always able to determine the http referral (the web page from which Quick Links was accessed). This information was required in the hopes of strengthening security and preventing the script from being used for non-library or potentially hostile purposes. In the earlier logs the absence of an http referral hovered around $1.5 \%$. Based on that volume an alternative was developed that routed these users to a page from which they could access the resources listed on Quick Links. In the Fall $2004 \log$ this had increased to almost $3.5 \%$. This increase is most likely attributable to end user security concerns and a proliferation of personal firewalls. Based on this increase, a new approach has been developed whereby http referral data is no longer required. Taken together, for the Fall of 2004, 5\% of the Quick Link activity was not completely successful, either through selecting the menu option or being routed to a secondary page due to lack of an http referral.

\section{Referral Data in the Fall 2004 Transaction Log}

Unlike the earlier logs where only the absence of http referrals were recorded, the Fall $2004 \log$ also contained specific page referral data. Each entry in the transaction log includes a separate column with the web page from which the choice was made. This was seen as especially important to the Information Technology Work Group, since Quick Links were present on so many of the library web pages. This data was seen as a way to determine how often Quick Links were accessed from pages other than the homepage as well as looking for patterns of use from different pages.

A total of 389 distinct urls were recorded as being a source from which Quick Links were accessed. Despite this large number, the majority of requests came from a small set of pages. The library homepage accounted for $76 \%$ of all referrals, and the top five referral pages alone accounted for just shy of $90 \%$ of all Quick Link activity. Since such a large percentage of use came from the library homepage, the pattern of Quick Link usage on the library home page was similar to the usage found in the global analysis.

Among the other top referral pages, there were some interesting differences in Quick Link usage. On these top referral pages, users gravitated even more heavily toward the most frequently used Quick Links. From the Research page, a primary entryway to databases (http://www.library.vcu.edu/research), InfoTrac was selected from Quick Links $41 \%$ of the time. Likewise from the Catalog entry page (http://www.library.vcu.edu/catalog), InfoTrac was used $48 \%$ of the time. In both cases this is significantly more than the $27 \%$ selection recorded in the global analysis. The portrait of Quick Link usage from the homepage of the Tompkins-McCaw Library for the Health Sciences also points toward a distinct research culture. A small percentage $(5 \%)$ 
selected the popular aggregator InfoTrac, whereas the number one choice was MEDLINE/Pubmed (47\%) followed by the nursing and allied health database CINAHL $(21 \%)$.

The Quick Links for services were used much less frequently than from the library homepage. Whereas Blackboard was accessed $7.4 \%$ of the time from the homepage, it was not even selected more than $0.5 \%$ of the time from the other top pages. Similarly, "E-mail" while at $12.8 \%$ from the homepage, was only selected $3.2 \%$ of the time from the Research page and 1\% of the time from the Catalog page. In general, the referral data challenges the assumption that Quick Links are needed as a persistent choice throughout the site. The referral data can also help in determining what content may need to be added to specific secondary pages, if Quick Links were to be removed.

\section{Comparing the Fall 2004 Transaction Log with Web Server Logs}

Data from the transaction log in combination with web server logs can be beneficial both for verification and cross-reference. For example, in the previously discussed example, a decline in Quick Link usage for "Ejournals" was softened by the web server logs showing an increase in accesses to the Ejournal page (most probably through the direct link to Ejournals that was added on the homepage). There were a total of 108,559 entries in the Fall 2004 transaction log, with almost $76 \%(82,415)$ of those coming from the library home page. In and of itself this seems like a significant number, but by looking at the web server logs one can begin to see how much Quick Links may be used in comparison with the rest of the site. During the same period as the transaction log, there were 777,689 accesses to the library homepage in the web server logs. Thus, the use of Quick Links from the homepage totaled slightly more than $10 \%$ of the total accesses to the library homepage itself.

Taken further, this cross analysis between the transaction and server logs can look more critically at the top Quick Link choices. From the transaction log referral data, there were 21,636 InfoTrac requests from the Quick Links menu on the home page. Divided by the total number of homepage accesses during the transaction log, this measures $2.78 \%$ of the library homepage accesses. The top two Quick Link choices (InfoTrac and Pubmed) were accessed 35,713 from the library home page via Quick Links. This is equal to $4.59 \%$ of homepage accesses.

The web server logs in and of themselves can also provide a check of some of these assumptions. The script that is launched each time a Quick Link is chosen is recorded in the web server logs. For the calendar year 2004, these logs record 2,257,244 homepage accesses and 326,114 Quick Link accesses. Using the 76\% homepage referral figure from the $2004 \log$ analysis we are left with 247,846 Quick Links accesses or 10.98\% of all home page accesses. This mirrors the figure derived from comparing the transaction log with the server log. Likewise, assuming 44\% of Quick Link Activity is focused toward the top two choices (InfoTrac and Pubmed); we derive 109,052 Quick Links to these databases from the home page or $4.83 \%$ of home page accesses. Again, this number is very comparable to the previously estimated $4.59 \%$ in comparing Fall 2004 data. In short, 
it appears that upwards to 1 in 10 accesses to the home page branches off to Quick Links, and that close to half of those Quick Links results in a link out to either InfoTrac or MEDLINE/Pubmed [Table 3].

Quick Links can also be seen in the 2004 server logs right alongside our "top level" pages. The standard library header offers tabs to Home/Research/Catalog/Services/Forms/My Library/Help [figure 1]. Data for My Library links are not in the web server logs as this page resides on a different ssl enabled server. Quick Links usage $(326,114)$ is especially larger than the Services $(44,439)$, Forms $(36,599)$, and Help $(16,815)$ pages. The Quick Link usage is on the same scale as both Research $(250,420)$ and Catalog $(292,563)$ [Table 4].

\section{Sticky or Transparent}

It seems inescapable that there is significant use of the Quick Links feature. This use is tilted heavily from the library homepage, and favors a few of the library databases. In addition, non-library selections such as E-mail and Blackboard have seen more Quick Links use than library specific pages such as Sitemap or Research Guides. What type of judgments do we draw from such analysis? What about all of the other subscription databases and library services that are not listed on Quick Links? Does Quick Links limit the view of resources or serve to get people where they would wind up going anyway? If some Quick Links are so popular, why not simply link to them more directly on the homepage instead? Is there an ideal balance that library websites should aspire to in terms of accesses to internal web pages versus linking out to external resources? These questions echo familiar library web design struggles. They also speak to the profession's ongoing aspirations to both save the time of the reader and connect him or her to the appropriate information resource (Ranganathan, 1931). By leveraging transaction and server logs, libraries can in part gauge how well their websites are meeting these goals.

As of this writing, the VCU Libraries Information Technology Work Group is considering these issues alongside the data from the transaction and server logs. Based on this data and professional consensus, a new Quick Link menu should soon be fielded.

\section{Works Cited}

Davis, P. M. (2004). Information-seeking behavior of chemists: A transaction log analysis of referral URLs. Journal of the American Society for Information Science and Technology, 55(4), 326-332.

Ranganathan, S. R. (1931). The five laws of library science. Madras; London: The Madras Library Association; E. Goldston. 


\section{Tables and Figures}

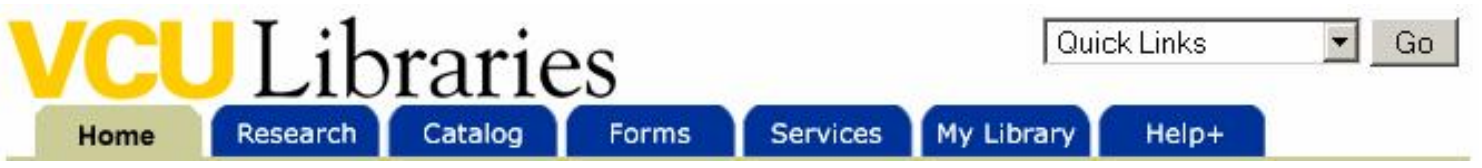

Figure 1. Standard VCU Libraries Header with Quick Links

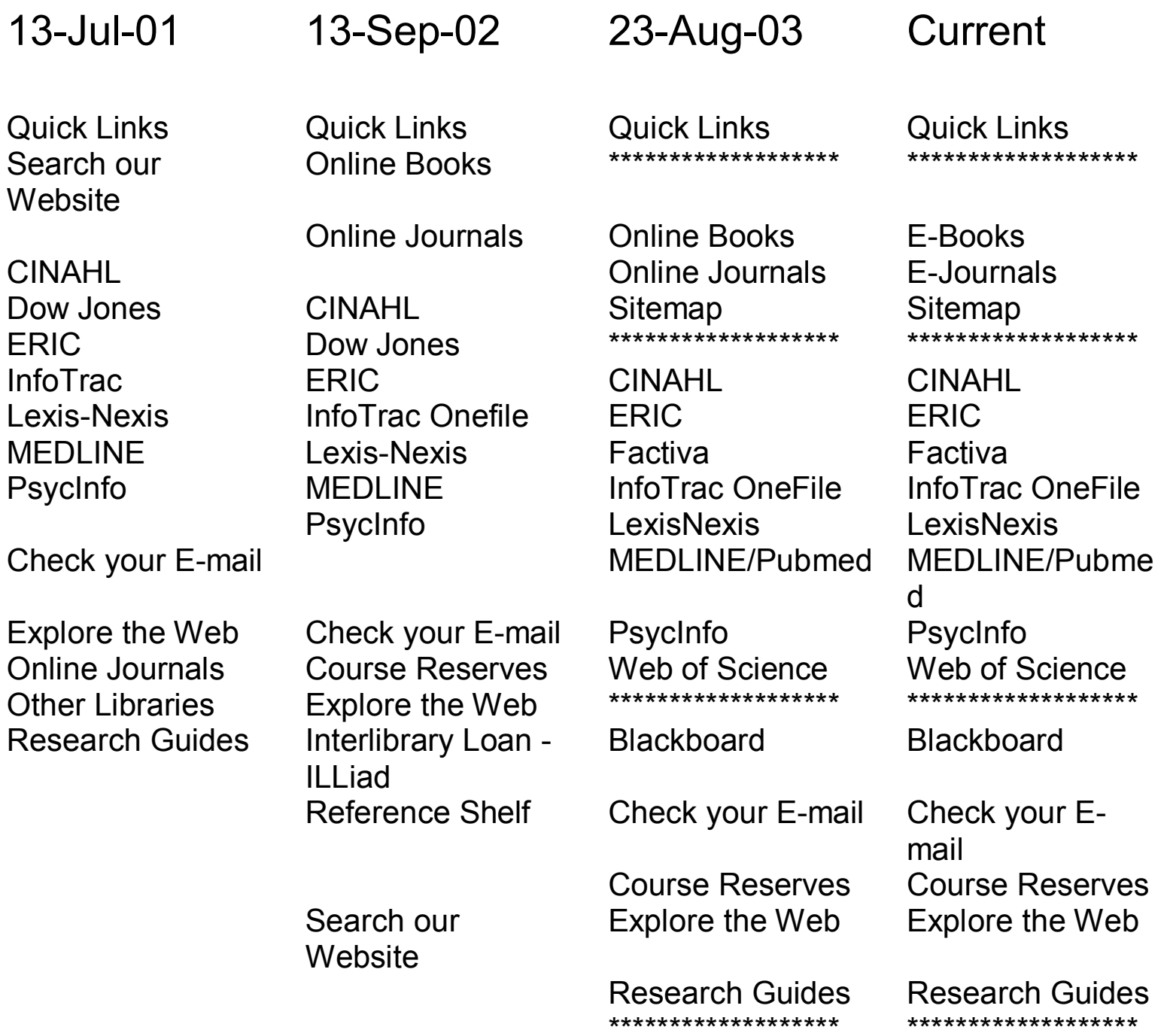

Table 1. Evolution of Quick Links over time 
InfoTrac Onefile

MEDLINE/Pubmed

Check your E-mail

Lexis

Ejournals

Blackboard

(Added May 2003)

Cinahl

Psyclnfo

Factiva

ERIC

menu

Course Reserves

Ebooks

Web of Science

Research Guides

(Added May 2003)

Search the Internet

Sitemap

(changed name in 2002

from Search our

Website, moved to top of list May 2003)

Spacer

Illiad

(Dropped May 2003)

Electronic Ref Shelf

(Dropped May 2003)

Error--no http Referer

(Recorded separately in

Fall $2004 \log$ ) $1^{\text {st }} \log$

9/2002-11/2002

$(72,446$

transactions)

$2^{\text {nd }} \log$

12/2002-

$4 / 2003$

$(97,332$

transactions)

$28.1 \%$

12.9

11.5

9.6

15.1

NA

NA

$27.1 \%$

12.5

12.3

10.3

15.7

$3^{\text {rd }} \log$

9/10/2004-

$12 / 1 / 2004$

(108,559

transactions)

Table 2. Percentage of Quick Link usage from 3 separate transaction logs.

\section{7}

3.1

2.3

1.4

1.6

1.4

1.7

1

1.3

0.8

0.02

$0.4 \quad 0.6 \quad \mathrm{NA}$

$0.4 \quad 0.6 \mathrm{NA}$

$\begin{array}{lll}0.5 & 0.4 \mathrm{NA}\end{array}$

$\begin{array}{ll}0.5 & 0.4 \mathrm{NA}\end{array}$

1.2

0.8

0.05
$27.6 \%$

16.8

10.5

9.7

9.5

6.1

5.1

3.1

2.4

1.5

1.5

1.8

1.2

1.1

0.7

0.7

0.2

0.03

1.5

1.5

3.5 
Homepage accesses

Quick Link accesses

Estimate $76 \%$ of Quick Links

from homepage

Quick Links homepage activity

as a percentage of homepage

accesses

Estimate $44 \%$ of Quick Links

using Infotrac+Pubmed from

Home Page

InfoTrac+Pubmed Quick Links

Homepage activity as a

percentage of homepage

accesses

Table 3. Estimates of
$2,257,244$

326,114

247,846

$10.98 \%$

109,053

$4.83 \%$

Sources: accesses from web server logs, percentile estimates from Fall 2004

transaction log.

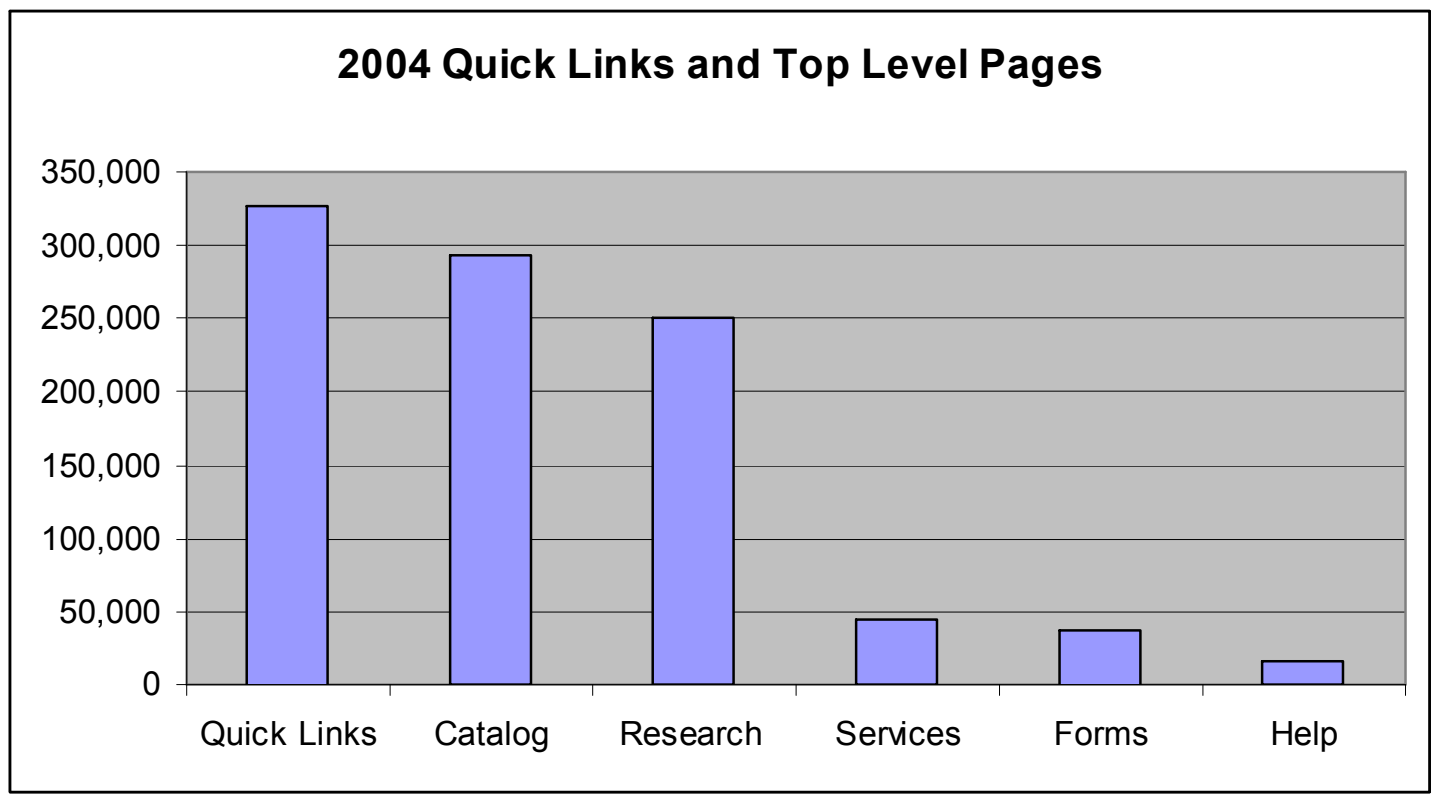

Table 4. Quick Link activity compared to other top-level pages for the year 2004. Source: web server logs. 